\title{
Chemical evidence for the pairing of some iron meteorites
}

\author{
MaKi HoASHi ${ }^{1}$, Robert R. BROOKS ${ }^{2}$, DOUglas E. Ryan ${ }^{3}$, \\ JiRI HOLZBECHER ${ }^{3}$ and ROGER D. REEVES ${ }^{4}$ \\ Geological Survey of Canada, 601 Booth St, Ottawa, Canada K1A OE8 ${ }^{1}$, \\ Department of Soil Science, Massey University, Palmerston North, New Zealand ${ }^{2}$, \\ Trace Analysis Research Centre, Department of Chemistry, Dalhousie University, \\ Halifax, Nova Scotia, Canada B3H $4 \mathrm{~J}^{3}$ and \\ Department of Chemistry and Biochemistry, Massey University, Palmerston North, New Zealand ${ }^{4}$
}

(Received February 22, 1993; Accepted July 21, 1993)

\begin{abstract}
On the basis of compositional evidence from abundances of $\mathrm{Ni}$ and noble metals in iron meteorites, pairings of a number of meteorites were examined. It was concluded that: in group IIICD, Carlton is paired with Lamesa; in group IIB, "Onnum Valley" (DP88020) and "CM66" (DP88023) are paired with the Derrick Peak shower; in group IVA, Railway and "G2011" are paired with Gibeon; and in group IIIE, Paneth's Iron is paired with Coopertown rather than with Burlington or Staunton.
\end{abstract}

\section{INTRODUCTION}

Wasson (1974) defined a paired set of meteorites as specimens accorded separate entries in catalogues, but which on detailed study appear to be parts of the same fall. Hey (1966) used the word "paired" in a less restrictive sense to indicate meteorites that are possibly fragments of the same fall. Pairing of meteorites has also been discussed by Malvin et al. (1984) who have used mineralogical as well as chemical criteria for such pairings. The most common reason for the separate status of related meteorites is removal of a piece of a fall from the area where a meteorite shower had landed. Removal was often effected by native peoples. For example, the North American Indians carried pieces of iron meteorites on their travels or nomadic wanderings believing them to bestow the carrier with supernatural powers. In this way, pieces of Canyon Diablo were scattered throughout Arizona (Wasson, 1968). The Eskimos of Greenland traded pieces of the Cape York shower throughout the northern parts of the Americas and samples of cold-worked tools made from this iron have been found as far away as Hudson Bay (Buchwald, 1975).

Since many meteorites within a group are similar in chemical and structural composition, it can be difficult to establish pairings for some specimens. In the past when only structural parameters such as kamacite band widths could be used, the task of pairing meteorites was extremely difficult. It was moreover rendered even more difficult, when, as often happened with old specimens, the metal was reworked by human activities so that parameters such as hardness were thereby altered. However, following the spectacular advances in analytical chemistry over the past $\mathbf{3 0}$ years, particularly as it concerns the noble metals, the meteorite researcher has at his disposal a much greater range of parameters that can be used for classification and pairing purposes.

It is true that other parameters such as formation ages, cosmic ray exposure ages, fall ages, and isotopic anomalies, might be used to improve the accuracy of pairing predictions. However, such data were lacking for either of both of suggested pairings and the emphasis in this paper is therefore on chemical composition as well as morphology and kamacite band widths 
as diagnostic criteria.

During the earlier years of meteorite analysis only the noble metals $\mathrm{Au}$ and $\mathrm{Ir}$ were quantified with any frequency and the analyst relied on instrumental neutron activation analysis (INAA) or radiochemical NAA (RNAA) for this purpose (Smales et al., 1967). Later the NAA methods were used to extend the range of analyses to Os, $\mathrm{Ru}$, and Pt (Pernicka and Wasson, 1987). Quantification of Ru and Pt by RNAA is nevertheless a complicated technique and reproducibility and limits of detection for these elements are not as good as for Ir.

Recently, methods utilizing graphite furnace atomic absorption spectrometry (GFAAS) have been developed as an alternative to INAA or RNAA for the quantification of Ru, Pt, and Pd (Hoashi et al. 1990, 1993). Furthermore, Ryan et al. (1990) have developed a satisfactory method for determining Rh by INAA. It is therefore possible to quantify all the noble metals (except Ag) by RNAA, INAA, or GFAAS. During the past three years we have quantified about 130 iron meteorites for all the above elements (Hoashi et al. 1993) and have used this pool of data to make observations on a number of meteorites that are probably paired (Tables 1 and 2 and Fig. 1) and report our findings below. The emphasis of this work has been on chemical methods of classification as opposed to physical and morphological procedures. In most cases our data have served to corroborate rather than contradict the earlier classification methods and the latter have been taken into account when making the final assessment.

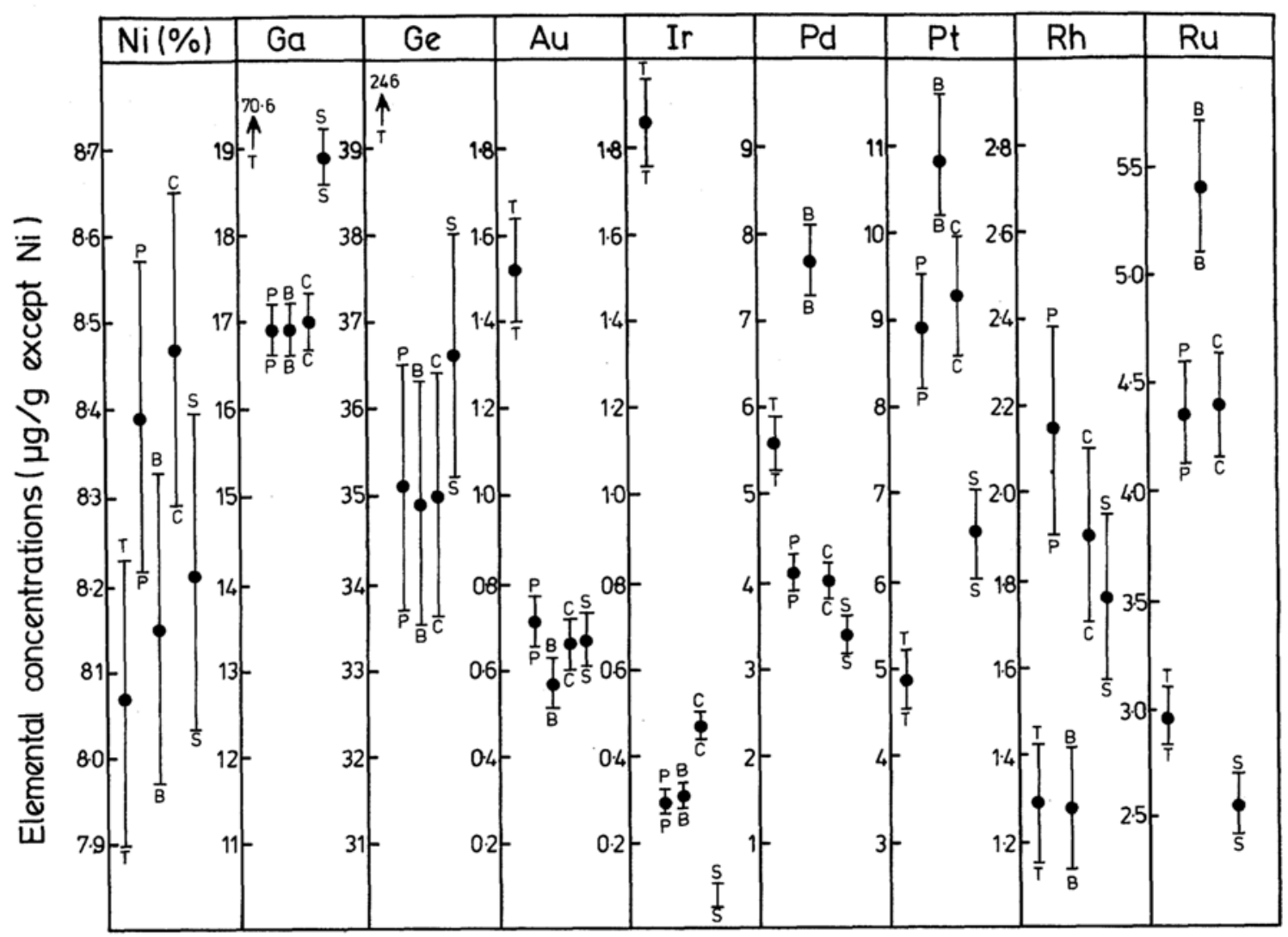

Fig. 1. Comparison of elemental abundances in Paneth's Iron and potential candidates for pairing. T-Toluca, $P$-Paneth's Iron, B-Burlington, C-Coopertown, S-Staunton. 
Table 1. List of meteorites studied (all were finds)

\begin{tabular}{|c|c|c|c|c|c|c|c|}
\hline Name & Group & Type & Band width & Date \& location of find & Co-ordinates & Mass & Source \\
\hline Carlton & IIICD & Of & $0.20 \mathrm{~mm}$ & 1887-Texas & $31.55 \mathrm{~N} 98.2 \mathrm{~W}$ & $81 \mathrm{~kg}$ & AMNH \\
\hline Lamesa & IIICD & Of & $0.30 \mathrm{~mm}$ & 1981-Texas & $32.53 \mathrm{~N} 101.53 \mathrm{~W}$ & $17 \mathrm{~kg}$ & WZ \\
\hline DP88020 & IIB & Ogg & $5-8 \mathrm{~mm}$ & 1988-Antarctica (88020) & 80.5S $156.25 \mathrm{E}$ & $0.416 \mathrm{~kg}$ & $\mathrm{CM}$ \\
\hline DP78012 & IIB & Ogg & $5-8 \mathrm{~mm}$ & 1978-Antarctica (78012) & 80.5S $156.25 \mathrm{E}$ & $320 \mathrm{~kg}$ & WU \\
\hline DP88023 & IIB & Ogg & $5-8 \mathrm{~mm}$ & 1988-Antarctica (88023) & 80.5S $156.25 \mathrm{E}$ & $0.076 \mathrm{~kg}$ & $\mathrm{CM}$ \\
\hline Gibeon & IVA & Of & $0.30 \mathrm{~mm}$ & 1836-Namibia & $25.30 \mathrm{~S} 18 . \mathrm{E}$ & 21 tonnes & CMS \\
\hline G2011 & IVA & Of & $0.30 \mathrm{~mm}$ & 1989-Namibia & Unknown & $?$ & MGS \\
\hline Railway & IVA & Of & $0.30 \mathrm{~mm}$ & 1933-Namibia & Unknown & $47 \mathrm{~kg}$ & MGS \\
\hline Toluca & IAB & $\mathrm{Og}$ & $1.4 \mathrm{~mm}$ & 1776-Mexico & $19.34 \mathrm{~N} 99.34 \mathrm{~W}$ & 2.1 tonnes & FM \\
\hline Paneth's Iron & IIIE & $\mathrm{Og}$ & $1.5 \mathrm{~mm}$ & 1873-Unknown & Unknown & $150 \mathrm{~kg}$ & BMNH \\
\hline Burlington & IIIE & Om & $1.3 \mathrm{~mm}$ & 1819-New York State & $42.45 \mathrm{~N} 75.11 \mathrm{~W}$ & $68 \mathrm{~kg}$ & USNM \\
\hline Coopertown & IIIE & $\mathrm{Og}$ & $1.5 \mathrm{~mm}$ & 1860-Tennessee & $36.25 \mathrm{~N} 87.0 \mathrm{~W}$ & $17 \mathrm{~kg}$ & AMNH \\
\hline Staunton & IIIE & $\mathrm{Og}$ & $1.6 \mathrm{~mm}$ & 1869-Virginia & $38.13 \mathrm{~N} 79.3 \mathrm{~W}$ & $44 \mathrm{~kg}$ & BMNH \\
\hline
\end{tabular}

Sources: AMNH-American Museum of Natural history, New York; WZ-Walter Zeitschel; CM-Canterbury Museum, Christchurch, New Zealand; WU-Waikato University, Hamilton, New Zealand; CMS-Center for Meteorite Studies, Tempe, Arizona; MGS-Museum of the Geological Survey, Pretoria, South Africa; FM-Field Museum, Chicago; BMNH-British Museum (Natural History), London; USNM-United States National Museum, Smithsonian Institution, Washington.

Table 2. Elemental abundances ( $\mu \mathrm{g} / \mathrm{g}$ except $\mathrm{Ni}$ ) in iron meteorites

\begin{tabular}{lccccccccc}
\hline Meteorite & $\mathrm{Ni}(\%)$ & $\mathrm{Ga}$ & $\mathrm{Ge}$ & $\mathrm{Ru}$ & $\mathrm{Ir}$ & $\mathrm{Rh}$ & $\mathrm{Pd}$ & $\mathrm{Pt}$ & $\mathrm{Au}$ \\
\hline Carlton & $13.5^{1}$ & $11.4^{1}$ & $8.6^{1}$ & 0.098 & 0.079 & 0.36 & 15.2 & 0.104 & 1.76 \\
Lamesa & $12.9^{1}$ & $13.3^{1}$ & $11.8^{1}$ & 0.105 & 0.036 & $<0.30$ & 14.4 & 0.106 & 1.75 \\
DP88020 & 6.50 & n.d. & 159 & 3.24 & n.d. & n.d. & 3.18 & 2.32 & n.d. \\
DP78012 & 6.54 & n.d. & 160 & 3.94 & $<0.01$ & 2.45 & 3.32 & 2.84 & 1.15 \\
DP88023 & 6.50 & n.d. & 162 & 3.91 & n.d. & n.d. & 2.46 & 2.52 & n.d. \\
Gibeon & 7.68 & 1.97 & 0.11 & 3.70 & 1.86 & 1.16 & 3.32 & 6.72 & 1.00 \\
G2011 & 7.58 & n.d. & $<0.10$ & 2.01 & 1.88 & 0.97 & 4.30 & 6.58 & 0.98 \\
Railway & 7.82 & 1.99 & 0.12 & 1.90 & 1.53 & 0.80 & 4.76 & 8.16 & 0.72 \\
Toluca & 8.07 & 70.6 & 246 & 2.96 & 1.86 & 1.28 & 5.56 & 4.84 & 1.52 \\
Paneth's Iron & $8.39^{1}$ & 16.9 & 35.1 & 4.36 & 0.29 & 2.15 & 4.12 & 8.86 & 0.71 \\
Burlington & 8.15 & 16.9 & 34.9 & 5.40 & 0.30 & 1.27 & 7.72 & 10.80 & 0.57 \\
Coopertown & 8.47 & 17.0 & 35.0 & 4.42 & 0.51 & 1.90 & 3.96 & 9.24 & 0.66 \\
Staunton & 8.21 & 18.9 & 36.6 & 2.57 & 0.07 & 1.76 & 3.40 & 6.52 & 0.67 \\
Limit of det. & 0.005 & 1.0 & 0.1 & 0.01 & 0.01 & 0.20 & 0.005 & 0.05 & 0.10 \\
r.s.d. & $2 \%^{3}$ & $2 \%{ }^{3}$ & $3.9 \%$ & $5.2 \%$ & $5.7 \%$ & $10.8 \%$ & $5.0 \%$ & $7.3 \%$ & $8.2 \%$ \\
\hline
\end{tabular}

1 Data from Malvin et al. (1984)

2 Calculated for concentrations ten times the limit of detection.

3 Estimate, $n . d .=$ not determined.

NB: Except where otherwise stated, abundance for Ni and Ga are from Wasson (1974).

All Ge values are also from this source except for the Derrick Peaks data which are our own.

\section{Analytical Procedures}

Except where otherwise stated in Table 2, abundance data for $\mathrm{Ni}$ and $\mathrm{Ga}$ were taken from Wasson (1974). The same source was used for most of the Ge data except for values for the three Derrick Peaks specimens.

Germanium in the above three meteorites was determined by hydride generation atomic absorption spectrometry using the method of Guo 
and Brooks (1990).

Ruthenium was determined by the method of Hoashi et al. (1990) and involved oxidation of $\mathrm{Ru}$ to its tetroxide using $\mathrm{NaIO}_{4}$. The complex is extracted into chloroform and the organic phase analysed by graphite furnace atomic absorption spectrometry (GFAAS). This procedure avoids loss of $\mathrm{Ru}$ as the volatile tetroxide as the complex in chloroform is more stable than the tetroxide in an aqueous medium. Experimentation showed that there was no loss of Ru when a charring temperature of $400^{\circ} \mathrm{C}$ was used in the graphite furnace program. Analysis of 6 replicates of the North Chile iron meteorite gave a mean of $20.0 \mu \mathrm{g} / \mathrm{g}$ compared with the value of $19.3 \mu \mathrm{g} / \mathrm{g}$ obtained by Pernicka and Wasson (1987).

Palladium and $\mathrm{Pt}$ were determined by GFAAS after extraction of their iodo complexes into methylisobutyl ketone using a modification of the method of Brooks and Lee (1987).

Instrumental neutron activation analysis (INAA) was used for the quantification of $\mathrm{Rh}$ using the procedure described by Ryan et al. (1990). Gold and Ir were determined by the same workers using standard INAA procedures.

Limits of detection and precisions for each elemental analysis are summarised in Table 2.

Numerous iron meteorites have been analysed for Ru, Pt, and Pd by Hoashi et al. (1993). These include many that had previously been analysed by INAA and radiochemical NAA methods.

Typical values $(\mu \mathrm{g} / \mathrm{g})$ for Pt (data from Pernicka and Wasson, 1987 in parentheses) were: Canyon Diablo 6.2 (5.8), Odessa 5.67 (5.5), North Chile 23.1 (23.0), Carbo 21.1 (21.0), and Bella Roca 1.42 (1.40).

For Ru (comparative values for North Chile already shown above) the corresponding data were: Henbury 10.2 (11.7), Trenton 7.56 (7.0), Carlton 0.098 (0.103), and Klamath Falls 0.99 (0.96).

Comparative data for Pd were much more difficult to obtain because of the lack of NAA data for this element. However when our values were compared with the NAA data of Smales et al. (1967), the following results (Smales data in parentheses) were obtained: Colfax 4.8 (4.6), Arispe 2.4 (2.4), Coahuila 1.92 (2.0), and Gibeon 3.32 (3.5).

The reader is referred to Hoashi et al. (1993) for additional comparative values for our abundance data in iron meteorites.

\section{Results AND Discussion}

\section{Carlton and Lamesa}

Carlton was ploughed up as a $80 \mathrm{~kg}$ mass by a farmer in Texas in 1887, whereas Lamesa (17 $\mathrm{kg}$ ) was discovered about $300 \mathrm{~km}$ away 80 years later, also in Texas. Although this appears to be a large distance, Wasson (1968) showed that Canyon Diablo specimens of similar mass to Lamesa had been transported equally large distances. The 80 years time difference in the finds has no significance.

Both Carlton and Lamesa are type of meteorites (Table 1) and although their kamacite band widths of 0.2 and $0.3 \mathrm{~mm}$ respectively are slightly different, this difference is small and may not be significant since values are quoted to only one significant figure. Graham et al. (1985) suggested that these two meteorites were paired on the basis of their content of $\mathrm{Ni}, \mathrm{Ga}, \mathrm{Ge}$, and Ir. Malvin et al. (1984) have also paired these two meteorites on the basis of compositional similarities involving 12 elements $(\mathrm{Ni}, \mathrm{Cr}, \mathrm{Co}$, $\mathrm{Cu}, \mathrm{Ga}, \mathrm{Ge}, \mathrm{As}, \mathrm{Sb}, \mathrm{W}, \mathrm{Re}, \mathrm{Ir}$, and $\mathrm{Au})$. Our additional data for $\mathrm{Au}, \mathrm{Pd}, \mathrm{Pt}$, and $\mathrm{Ru}$ support this pairing. Confidence limits for abundance data overlap for these five elements. Agreement for $\mathrm{Ir}$ is poor and this is because values are close to the limit of detection (l.o.d.) where precisions (relative standard deviation [r.s.d.]) can be an order of magnitude worse than the levels stated in Table 2 which are based on r.s.d. calculated for concentrations ten times the l.o.d. The Rh concentrations of 0.36 and $<0.30 \mu \mathrm{g} / \mathrm{g}$ are probably within the standard deviation of the mean assuming that the true value of the " $<0.30$ " number is close to $\mathbf{0 . 3 0}$. 
Derrick Peak, "CM66", and "Onnum Valley"

Antarctic meteorites are often located in the blue-ice fields on the windward side of mountain ranges. Ice is ablated away by the wind and leaves meteorites exposed that have moved hundreds of $\mathrm{km}$ from other parts of the ice sheet. This movement that has the effect of concentrating the meteorites in a small area, meaning that few, if any, specimens found are paired or related in any way. The Derrick Peak irons are different in that they were found on a remote nunatak free of ice and snow (McSween, 1987). The original 16 meteorites (DP 78001-78016) have been shown to be related to each other and are parts of the same fall (Clarke, 1982). Another two small irons were discovered by a New Zealand field party in the mid-1980s in Onnum Valley near Derrick Peak. These type Ogg meteorites were originally named "CM66" and "Onnum Valley" and on the basis of their morphology and mineralogy as well as $\mathrm{Ge}, \mathrm{Ni}$, and Co determinations (carried out in our laboratory), have been assigned to the Derrick Peaks fall and renamed DP88023 and DP88020 by Kirkbride et al. (1991). Our further analyses of these two meteorites and of DP78012 for comparison, are given in Table 2 . From abundances of five elements determined in all three specimens ( $\mathrm{Ni}, \mathrm{Ge}, \mathrm{Ru}, \mathrm{Pd}$, and $\mathrm{Pt}$ ), they are clearly all members of the same shower and are paired according to the definition of Hey (1966).

\section{Railway, “G2011", and Gibeon}

The Museum of the South African Geological Survey in Pretoria has provided us with samples of Railway (South African Railways) (IVA) and an unknown iron labelled "G2011." Both of these were found in Namibia. The data in Tables 1 and 2 seem to confirm that these two specimens are pieces of Gibeon. All three are type of and have the correct kamacite band width of $0.3 \mathrm{~mm}$ (Table 1).

Agreement between Gibeon and G2011 for abundances of $\mathrm{Ni}, \mathrm{Ge}, \mathrm{Ir}, \mathrm{Rh}, \mathrm{Pt}$, and $\mathrm{Au}$ is very close. Agreement for Pd is not as good, but it has been our observation that this element, which like As behaves as a chalcophile in iron meteorites (Scott, 1972), tends to be more variable within a meteorite sample than are the siderophile noble metals (Haack et al. 1993).

When Railway is compared with Gibeon, good agreement was found for abundances of $\mathrm{Ni}, \mathrm{Ga}$, and $\mathrm{Ge}$ though not for the remainder of the elements. Because of the large size of Gibeon and its presence as about 77 different masses subjected to different degrees of heating when the parent body broke up upon entering the earth's atmosphere, it is to be anticipated that the separate masses would be more inhomogeneous than in the case of a single fall so that minor differences in the noble metal content would therefore be expected. Even in the case of a single fall such as Armanty (Wasson et al. 1988) and Canyon Diablo (Wasson and Ouyang, 1990) variation in the abundance of Ir amounted to about $7 \%$.

In view of the above findings and arguments, we propose that Railway is probably a part of Gibeon as suggested by Buchwald (1975) and there seems little doubt that G2011 is also a part of this same meteorite.

\section{Paneth's Iron and other Group IIIE meteorites}

One of the most intriguing questions in meteorite classification relates to Paneth's iron, first named as such by Buchwald et al. (1974). The three existing slices of this IIIE meteorite were, until fairly recently, believed to be part of Toluca (IAB) since both are coarse octahedrites $(\mathrm{Og})$. Buchwald (1975) was puzzled by the structures of the samples held in the Natural History Museum (London), the Institute of Geological Sciences (London), and the Max Planck Institute in Mainz. He concluded from structural observations, that the meteorite from which the three slices had been taken belonged to Group IIIE and not to IAB and proposed the name Paneth's Iron to honour one of the early investigators of this mass.

A further piece of evidence that Paneth's Iron was different from Toluca was the analyses of Smales et al. (1967) for "Toluca" that were in disagreement with analyses of other workers in spite of his record of quality work. His analyses 
had probably been carried out on the specimen from the Natural History Museum. Wasson (1974) also observed the disparate data and named this slice as "Pseudo Toluca."

John Calvert, a 19th Century collector and dealer was the purported discoverer of the Paneth Iron slices and represented them as separate finds from Africa, Brazil, and Dartmoor. According to Buchwald (1975) this gentleman was not noted for his integrity. When attempting to reassemble the meteorite, Buchwald found that a fourth slice was missing, as well as a $5-10 \mathrm{~kg}$ piece removed from the end of the original mass prior to slicing. The original mass probably weighed $100-150 \mathrm{~kg}$.

Buchwald compared available analytical data for Paneth's Iron against other IIIE meteorites (the meteorites which qualified for pairing according to probable provenance are fortunately few in number) and suggested that Paneth's Iron could be a part of Burlington which was found by a farmer in New York State in 1819 and originally weighed $50-100 \mathrm{~kg}$. The bulk of the material had disappeared before 1844 and only $5 \mathrm{~kg}$ of heated and altered material survives. The remainder was probably manufactured into iron implements by a blacksmith to whom the original mass had been taken after its discovery.

We have acquired three American IIIE irons known to have been part of collections in the mid-to-late $1800 \mathrm{~s}$. Our analyses (Table 2 and Figure 1) indicate that elemental concentrations in Paneth's Iron more closely resemble Coopertown than either Staunton or Burlington. From Figure 1 where error bars (based on the relative standard deviation of replicate analyses) are shown, it will be noted that among the elements determined, there is only one abundance discordancy (Ir) between Paneth's Iron and Coopertown, whereas there are five involving Burlington ( $\mathrm{Au}, \mathrm{Pd}, \mathrm{Pt}, \mathrm{Rh}$ and $\mathrm{Ru}$ ) and five for Staunton ( $\mathrm{Ga}, \mathrm{Ir}, \mathrm{Pd}, \mathrm{Pt}$, and $\mathrm{Ru}$ ). As might be expected all elements except Ni show discordancy for Toluca. In the case of $\mathrm{Ni}$, the error bars seem high because of the additional uncertainty of sampling error because of the extreme inhomogeneity of this element in iron meterorites.
Physical characteristics such as hardness of the kamacite crystals are not very helpful for pairing because two of the irons (Burlington and Paneth's Iron itself) have been reworked by human intervention (Burlington seems once to have been used as a blacksmith's anvil). The question of reworking of meteoritic material has often been raised when the reliability of chemical analysis or morphology as diagnostic parameters have been considered. However, since Ge and all of the platinum group metals (PGM) are extremely involatile, there is little likelihood of them having been lost during the reworking stage, though the same cannot be said for morphological features such as widths of kamacite bands. Based on the abundance data for only refractory Ge and the PGM, it appears that Burlington is not paired with Paneth's iron.

The total mass of Coopertown $(17 \mathrm{~kg})$ is too small for it to be considered as the parent material for Paneth's Iron and in any case its entire mass is accounted for in collections. However, Buchwald (1975) did not rule out the possibility that Paneth's Iron could be a paired fall with either Coopertown, which fell in Tennessee, or Staunton which fell in Virginia. The chemical evidence in Table 2 and Figure 1 seems to indicate that Paneth's Iron is indeed a paired fall with Coopertown and that Calvert might have discovered or otherwise obtained, a large mass from Tennessee and produced his frauds from it. We therefore recommend that Coopertown and Paneth's Iron be considered paired.

\section{Conclusions}

It is concluded that our data demonstrate the value of analyses of iron meteorites for all the noble metals except silver, as well as for highly diagnostic elements such as $\mathrm{Ge}$ and $\mathrm{Ga}$, in order to be able to pair meteorites and to detect cases of fraud and/or mislabelling. There is still much to be done in this field and we still have a number of unresolved cases to be considered in the future, but it is clear that the analytical chemist will have an increasingly important role to play in this matter. This role is being enhanced by 
new developments in instrumentation as for example laser ablation ICP mass spectrometry for which meteorites are ideal samples.

Acknowledgments-We wish to express our sincere appreciation to the curators and museums listed in Table 1 for their generous supply of meteorite specimens for chemical analysis.

\section{REFERENCES}

Brooks, R. R. and Lee, B. S. (1987) The determination of platinum and palladium in rocks and soils by electrothermal atomic absorption analysis of extracts of their iodo complexes. Anal. Chim. Acta 204, 333-337.

Buchwald, V. F. (1975) Handbook of Iron Meteorites, University of California Press, Berkeley.

Buchwald, V. F., Hutchison, R. and Hall, J. M. (1974) Paneth's Iron, a new Group IIIE iron. Meteoritics 9, 307-311.

Clarke, R. C. (1982) The Derrick Peak, Antarctica, iron meteorites. Meteoritics 3, 129-134.

Graham, A. L., Bevan, A. W. R. and Hutchison, R. (1985) Catalogue of Meteorites, 4th Ed., British Museum (Natural History), London.

Guo, X. and Brooks, R. R. (1990) The use of hydride generation atomic absorption spectrometry for the determination of germanium in iron meteorites. Anal. Chim. Acta 228, 139-143.

Haack, H., Scott, E. R. D., Rubio, G. S., Gutierrez, D. F., Lewis, C. F., Wasson, J. T., Brooks, R. R., Guo, X., Ryan, D. E. and Holzbecher, J. (1993) Systematic chemical variation in large IIIAB iron meteorites: clues to core crystallization. Lunar Planet. Sci. Conf. Abs. (in press).

Hey, M. H. (1966) Catalogue of Meteorites. 3rd Ed., British Museum (Natural History), London.

Hoashi, M., Brooks, R. R. and Reeves, R. D. (1990) A graphite furnace atomic absorption method for the quantification of ruthenium in iron meteorites.
Anal. Chim. Acta 232, 317-321.

Hoashi, M., Brooks, R. R. and Reeves, R. D. (1993) Palladium, platinum, and ruthenium in iron meteorites and their taxonomic significance. Chem. Geol. 106, 207-218.

Kirkbride, M. P., Bradshaw, M. A. and Harmsen, F. J. (1991) Further finds of the Derrick Peak meteorite, Transantarctic Mountains, and implications for terrestrial age. Meteoritics 26, 213-216.

Malvin, D. J., Wang, D. and Wasson, J. T. (1984) Chemical classification of iron meteorites-X. Multielement studies of 43 irons, resolution of group IIIE from IIIAB, and evaluation of $\mathrm{Cu}$ as a taxonomic parameter. Geochim. Cosmochim. Acta 48, 785-804.

McSweeney, H. Y. (1987) Meteorites and their Parent Planets, Cambridge University Press, Cambridge.

Pernicka, E. and Wasson, J. T. (1987) Ru, Re, Os, Pt and $\mathrm{Au}$ in iron meteorites. Geochim. Cosmochim. Acta 51, 1717-1726.

Ryan, D. E., Holzbecher, J. and Brooks, R. R. (1990) Rhodium and osmium in iron meteorites. Chem. Geol. 85, 295-303.

Scott, E. R. D. (1972) Chemical fractionation in iron meteorites and its interpretation. Geochim. Cosmochim. Acta 36, 1205-1236.

Smales, A. A., Mapper, D. and Fouche, K. F. (1967) The distribution of some trace elements in iron meteorites as determined by neutron activation. Geochim. Cosmochim. Acta 31, 673-720.

Wasson, J. T. (1968) Concentrations of nickel, gallium, and iridium in Canyon Diablo and other Arizona octahedrites. J. Geophys. Res. 73, 32073211.

Wasson, J. T. (1974) Meteorites, Springer, New York.

Wasson, J. T. and Ouyang, X. (1990) Compositional range in the Canyon Diablo meteoroid. Geochim. Cosmochim. Acta 54, 3175-3183.

Wasson, J. T., Ouyang, X. and Wang, D. (1988) Compositional study of a suite of samples from the 28-t Armanty (Xinjiang) iron meteorite. Meteoritics 23, 365-369. 